\title{
The need for laughter therapy in pediatrics
}

Calheiros-Cruz $\mathrm{T}^{1,2}$, Fernández-Requejo $\mathrm{C}^{2}$, Parrado-Alonso $\mathrm{MJ}^{1,2}$, Lago-López $\mathrm{P}^{1,2}$, Ruibal-Azevedo $\mathrm{J}^{1,2}$, Villar-Fernández $\mathrm{B}^{3}$, ÁlvarezMartínez $\mathrm{MC}^{2}$, Paz-Otero $\mathrm{V}^{2}$, Fernández-Carrera $\mathrm{MC}^{2}$, Martínez-Rodríguez $\mathrm{MJ}^{2}$, Cameselle-Cortizo $\mathrm{L}^{1,2}$ and Cameselle-Teijeiro JF ${ }^{1,2}$

${ }^{1}$ Clinical Oncology Research Center ADICAM, Cangas, Spain

${ }^{2}$ Laugher Therapy School “ALENTO”, Vigo, Spain

${ }^{3}$ Northampton Community College, Pennsylvania, United States

Humor is a primordial part of our life, our evolution and genetics [1]. There is currently a growing interest in laugh therapy, the use of humor in health care and medicine, as a tool to educate, prevent and treat specific pathologies [2]. According to holistic and humanistic models of health care, this therapy allows for valuing, caring and treating the patient as a "whole" person, taking care of their mental and physical well-being. But the use of laughter as a therapy is not something new. The origins go as far back as the begining of civilizations, as noted in many writings, images and ancient rituals. For example, Chinese medicine has emphasized for thousands of years the value of laughter in group sessions to improve health, and in the middle ages, monkphysicians suggested the care of patients by three types of doctors: the "quiet" for healing, the "dyet" for eating and the "merry" for laughing [3].

Numerous studies, many initiated in the 1970's, have already shown that humor and laughter have positive effects on human physical, mental and well being [4-8], stimulates the immune system $[9,10]$, decreases stress associated with chronic diseases [11], increases pain tolerance $[12,13]$ and affects mental functions such as alertness, memory and anxiety [14]. It can be especially noted, that after 1988, with the american movie "Patch Adams" with Robin Williams inspired by the work of Dr Hunter [Patch], when laughter therapy quickly spread and was popularized around the world, with rapid growth in the presence of clowns in hospitals, particularly in pediatric settings in the last decade $[15,16]$

In the social context, laugh therapy allows for preventive interventions aimed to maximize health benefits in the family, in the community and at work. More than four years ago, our team of doctors, nurses and health care workers started a workshop on laugh therapy at a local organization for breast cancer patients [www.adicam.net], and we could observed in situ the efficacy of this therapeutic approach, with patients improved moods after the activity. As a consequence of the high demand that we received from the community to offer more workhops on this topic, we decided to create two years ago a permanent "Laugher Therapy School", in collaboration with twelve different local non-profit organizations for physically and/or intelectually disabled individuals. This "school" is allowing us to prepare many caregivers in laugh therapy and emotional inteligence; professionals who in return are helping us to spread this approach to different social and health care environments: schools, health centers, non-profit organizations for different types of illnesses, and hospitals.

We are currently in the process of meticulously investigating the benefits of laugh therapy in order to introduce this technique into the Primary Care health system. The main objective of our study is to evaluate if this therapy, when used in health care centers helps improve the health of the patients, stimulating the development of emotional intelligence and empathy. At the same time, we are exploring the design of the simplest, most effective [provide the desired effect], most efficient [minimal resources and time] and adequate methodology possible; to be able to integrate these laugh workshops into the Primary Care offered at our health centers. To help promote this approach, we have also produced the movie "Laughing Therapy in Primary Health Care", available (https://youtu.be/d1jLGgJab9g) in you tube channel.

In our study, we are finding that this therapy presents the following influences: improves the emotional well being of individuals with chronic diseases and/or physical or intelectual disabilities, eliminates psycological stereotypes, increases self esteem and facilitates the prevention and treatment of health worker's and caregiver's "burnout". The stimulation of emotional intelligence can reduce social phobias and prevent social isolation in some people, and it can help patients to better accept their medications. Laugh therapy positively influences the psycological and social behavior of patients with chronic diseases, improving their communication with health care workers.

In parallel to our workshops for adults, we are also offering laugh therapy workshops to sick children that are inpatients in the Pediatric Department of the Hospital. Our experience is allowing us to percieve that, although there are common benefits to the use of this therapy at all ages, the set goals and outcomes are very different for the different phases of human life - pediatric age [17-21], teens age and adult age.

Laughter is universally recognized and shared by all humans [22] and can be of great therapeutic value with no side effects. Therefore, We believe that we should try to encourage laugher even during the most difficult moments for patients, especially children, their families and heath care workers. Laugh therapy is a strategy that can also be considered a psycotherapeutic technique aimed to produce mental and emotional benefits with the use of laughter. In addition, we are also finding that this therapy is an excellent educative tool for the community to introduce themes for addressing social issues such as smoking, gender violence and bulling.

Correspondence to: Jorge F Cameselle Teijeiro, MD-PhD, Clinical Oncology Research Center ADICAM, Travesía de Vigo n 2, $2^{\circ}$ C VIGO, Spain, E-mail: videoprimaria@mundo-r.com

Key words: laugh therapy, humor, laughter, laugher therapy school, primary health care, emotional intelligence, empathy, hospitalized children, pediatrics

Received: March 09, 2018; Accepted: March 23, 2018; Published: March 26, 2018 
Specifically, the main benefits of laughter therapy that we observe in hospitalized children are two: first, we find that the levels of stress and anxiety decrease as we interact with them and their family members. During their hospitalization, children are separated from their comfortable home environment, and confronted with unfamiliar schedules and medical procedures. With laugher therapy, we are able to make the children see and feel the hospital as a less threatening place. In fact, it has been recently found that humor therapy decreases stress and changes cortisol levels in pediatric inpatients [23]. These results support the use of this technique in hospitals. A second benefit for children, described to us by their parents, is that, often, after being discharged from the hospitals, the children tell their close family members about the funny doctors and nurses that visited them and spent time with them, disguised and/or dressed as clowns. These memories are relayed with smiles and happiness, forgetting to mention all the invasive and traumatic surgeries they went through during the diagnoses and treatment of their diseases.

\section{References}

1. Polimeni J, Reiss JP (2006) The First Joke. Exploring the Evolutionary Origins of Humor. Evolutionary Phsychology 4: 347-366.

2. Mora-Ripoll R (2010) The therapeutic value of laughter in medicine. Altern Ther Health Med 16: 56-64.

3. Sacks, ZDS, Pell, GM (2013) At whom are we laughing? Humor in Romance Language Literatures. Cambridge Scholars 20: 1-57.

4. Lynn Erdman RN (1994) Laughter Therapy for Patients with Cancer. Journal of Psychosocial Oncology 11: 1-7

5. Adams P (2002) Humour and love: the origination of clown therapy. Postgrad Med J 78: $447-448$.

6. Leber DA, Vanoli EG (2001) Terapeutic use of humor: occupational therapy clinicians perceptions and practices. Am J Occup Ter 55: 221-226.

7. Joshua AM, Cotroneo A, Clarke S (1997) Humor and Oncology. Journal of Clinical Oncology 23: 645-648.

8. Carlberg G (1997) Laughter opens the door: Turning points in child psychotherapy. Journal of Child Psychotherapy 23: 331-349.
9. Berk LS, Felten DL, Tan SA, Bittman BB, Westengard J (2001) Modulation of neuroimmune parameters during the eustress of humor-associated mirthful laughter. Altern Ther Health Med 7: 62-76.

10. Sakai Y, Takayanagi K, Ohno M, Inose R, Fujiwara H (2013) A trial of improvement of immunity in cancer patients by laughter therapy. Jpn Hosp 32: 53-59.

11. Bennett MP (2003) The effect of mirthful laughter on stress and natural killer cell activity. Altern Ther Health Med 9: 38-45.

12. Weisenberg M, Raz T, Hener T (1998) The influence of film-induced mood on pain perception. Pain $76: 365-375$.

13. Vagnoli L, Caprilli S, Robiglio A, Messeri A (2005) Clown Doctors as a Treatment for Preoperative Anxiety in Children: A Randomized, Prospective Study. Pediatrics 116: 563-567.

14. Fry WF (1992) The physiologic effects of humor, mirth, and laughter. JAMA 267 1857-1858.

15. Spitzer P (2001) The clown doctors. Aust Fam Physician 30: 12-16

16. Koller D, Gryski C (2008) The Life Threatened Child and the Life Enhancing Clown: Towards a Model of Therapeutic Clowning. Evidence-Based Complementary and Alternative Medicine 5: 17-25.

17. Vessey JA (2003) Children's psychological responses to hospitalization. Annu Rev Nurs Res 21: 173-201.

18. Dowling JS (2003) Humor: a coping strategy for pediatric patients. Pediatr Nurs 28: 123-131.

19. Erickson SJ, Feldstein SW (2007) Adolescent humor and its relationship to coping defense strategies, psychological distress, and wellbeing. Child Psychiatry Hum Dev 37: $255-271$.

20. SC, Arriaga P (2010) The effects of clown intervention on worries and emotional responses in children undergoing surgery. J Health Psychol 15: 405-415.

21. Kain ZN, Mayes LC, Weisman SJ, Hofstadter MB (2000) Social adaptability, cognitive abilities, and other predictors for children's reactions to surgery. J Clin Anesth $12: 549$ 554 .

22. Sauter D, Eisner F, Ekman P, Scott SK (2015) Cross-Cultural Recognition of basic emotions through non-verbal emotional volalizations. PNAS 112: 2408-2412.

23. Sanchez JC, Echeverri LF, Londono MJ, Ochoa SA, Quiroz AF, Romero CR, Ruiz JO. Effects of a Humor Therapy Program on Stress Levels in Pediatric Inpatients. Hospital Pediatrics 7: 46-53.

Copyright: (C2018 Cruz C. This is an open-access article distributed under the terms of the Creative Commons Attribution License, which permits unrestricted use, distribution, and reproduction in any medium, provided the original author and source are credited. 